LOPES CA; BOITEUX LS; ESCHEMBACK V. 2015. Eficácia relativa de porta-enxertos comerciais de tomateiro no controle da murcha-bacteriana. Horticultura Brasileira 33: 125-130. DOI - http://dx.doi.org/10.1590/S0102-053620150000100020

\title{
Eficácia relativa de porta-enxertos comerciais de tomateiro no controle da murcha-bacteriana
}

\author{
Carlos A Lopes; Leonardo S Boiteux; Vlandiney Eschemback
}

Embrapa Hortaliças, C. Postal 218, 70351-970 Brasília-DF; carlos.lopes@embrapa.br

\section{RESUMO}

A murcha-bacteriana, causada por Ralstonia solanacearum, é uma das principais doenças das solanáceas em climas tropicais. Historicamente limitante à produção de tomate na Região Norte do Brasil, passou a ser uma séria ameaça ao tomateiro também nas Regiões Sul e Sudeste após a expansão do cultivo protegido. Embora fontes de resistência à doença tenham sido identificadas em germoplasma de tomateiro, cultivares comerciais resistentes ainda não estão disponíveis no mercado. O uso de porta-enxertos comerciais de tomate tem se popularizado pelo fato de, além de proteger a planta contra a doença, reduzir o problema de incompatibilidade associada ao uso de espécies/gêneros diferentes. O objetivo deste trabalho foi avaliar, em casa de vegetação, os níveis de resistência à murcha-bacteriana dos principais porta-enxertos comerciais de tomateiro, levando em conta a variabilidade patogênica de um conjunto de isolados de $R$. solanacearum. Foi observada uma clara distinção na incidência da doença entre os genótipos, e a reação foi do tipo isolado-dependente. Os porta-enxertos mais resistentes foram os híbridos 'Muralha' e 'Guardião', que não diferiram, para a maioria dos isolados, da linhagem 'Hawaii 7996' (padrão internacional de resistência) e apresentaram comportamento superior em relação aos híbridos 'Magnet' e 'Protetor'. Entretanto, todos os porta-enxertos avaliados sucumbiram à alta virulência do isolado CNPH 488 (Raça 1 / Biovar 2, coletado no estado do Paraná), que provocou a morte da totalidade das plantas. Quando avaliados em solo artificialmente infestado, com menor pressão de inóculo, 'Guardião' e 'Muralha' apresentaram, novamente, um desempenho significativamente superior ao de outros porta-enxertos. Os resultados obtidos reforçam que alguns porta-enxertos oferecem boa proteção do tomateiro contra a murcha-bacteriana sob condições normais de cultivo. Entretanto, em condições ambientais muito favoráveis à doença e/ou na presença de isolados muito virulentos, dificilmente o sistema de enxertia de tomateiro em tomateiro per se protegerá adequadamente a planta enxertada. Tal cenário exige medidas complementares e antecipadas de controle que visem a reduzir a população de $R$. solanacearum no solo ou escolha de ambiente menos propício à sua multiplicação.

Palavras-chave: Solanum lycopersicum, Ralsonia solanacearum, resistência genética, enxertia, tomate.

\section{ABSTRACT \\ Comparative effectiveness of commercial tomato rootstocks} to control bacterial wilt

Bacterial wilt, caused by Ralstonia solanacearum, is one of the main diseases of solanaceous crops in tropical regions, being the major limiting factor for tomato production in the North Region of Brazil. The disease has also been a constraint to tomato production under protected cultivation, which had solid expansion in the South and Southeast regions in the last decades. Although sources of resistance to bacterial wilt have been identified in S. lycopersicum germplasm, no resistant cultivars are available to growers. However, commercial rootstocks are available to protect scions against the disease, thus reducing the incompatibility associated to the use of different Solanaceae species/genera. The main objective of the present work was to evaluate the levels of resistance of a group of commercial hybrid/inbred tomato rootstocks to a diverse array of five $R$. solanacearum isolates (all obtained from infected tomato plants). A clear discrimination was observed among the evaluated rootstocks in relation to disease incidence. The phenotypic reaction of the tomato rootstocks was isolate-specific. The tomato hybrids 'Muralha' and 'Guardião' and the inbred line 'Hawaii 7996' (international resistance standard) were the rootstocks with best performance against the majority of the five $R$. solanacearum isolates, displaying significantly better resistance when compared with the hybrids 'Magnet' and 'Protetor'. However, all rootstocks were highly susceptible (100\% mortality) to the $R$. solanacearum CNPH 488 isolate (classified as race 1 / Biovar 2, collected in Paraná State, Brazil). The same set of rootstocks was also evaluated under artificially infested soil (with less intense inoculum pressure). The hybrids 'Guardião' and 'Muralha' repeated their good performance when compared with 'Magnet' and 'Protetor'. Our results reinforce the notion that under favorable environmental conditions and/or in the presence of highly virulent strains, the system based upon tomato scion grafted onto tomato rootstock might provide unsatisfactory levels of bacterial wilt control. Therefore, complementary and preemptive control measures will be necessary in order to reduce the initial inoculum pressure in the soil.

Keywords: Solanum lycopersicum, Ralstonia solanacearum, bacterial wilt resistance, grafting.

\section{(Recebido para publicação em 10 de março de 2014; aceito em 10 de outubro de 2014) (Received on March 10, 2014; accepted on October 10, 2014)}

$\mathrm{O}_{\mathrm{d}}^{\mathrm{s}}$ s primeiros registros da utilização da técnica da enxertia em solanáceas foram feitos na metade do século XX no Japão em que a berinjela cultivada (Solanum melongena) foi enxertada sobre uma berinjela silvestre
(S. integrifolium) (Kubota et al., 2008). A produção do tomateiro (Solanum lycopersicum) por meio de plantas 
enxertadas se intensificou, também no Japão, a partir da década de 1960. O emprego dessa técnica avançou rapidamente, viabilizando a produção intensiva dessa hortaliça em uma mesma área de cultivo (Lee \& Oda, 2003). Nos EUA, por sua vez, a enxertia de tomateiro em Datura stramonium, visando o controle de doenças causadas por patógenos de solo, não prosperou devido ao alto investimento de mão de obra e ao acúmulo nos frutos de tomate de alcaloides transportados a partir dos tecidos do porta-enxerto (Kubota et al., 2008).

No Brasil, as primeiras aplicações da enxertia no cultivo de hortaliças datam da década de 1950 na Região Norte. Imigrantes japoneses, fixados em Tomé Açu-PA, enxertavam tomateiro em solanáceas nativas da Região, como juna (Solanum toxicarium) e jurubeba (S. jurubeba), visando, especialmente, o controle da murcha-bacteriana, causada pela bactéria Ralstonia solanacearum (Galli et al., 1968). No entanto, a dificuldade de produzir tomate devido a vários outros problemas fitossanitários e a grande demanda por mão de obra para a realização da enxertia, levaram os produtores a abandonar a tomaticultura e concentrar seus esforços em cultivos alternativos, em especial a pimenta do reino, espécie muito bem adaptada à região (Galli et al., 1968).

Embora esforços tenham sido feitos no sentido de desenvolver novas cultivares de tomateiro para as condições do Nordeste (Silveira et al., 1999) e da Amazônia brasileiros (Cheng \& Silva, 1988; Noda et al., 1988; Cheng \& Chu, 2002; Pena et al., 2010), a murcha-bacteriana continua sendo o principal entrave à produção desta hortaliça, em especial na Região Norte (Noda et al., 1986; Lopes, 2009; Souza et al., 2013). Por outro lado, nas regiões tradicionalmente produtoras de hortaliças no Sudeste do país, a enxertia foi historicamente pouco utilizada, pois as cultivares disponíveis apresentavam fatores de resistência às principais doenças causadas por patógenos de solo, como murcha de fusário, murcha de verticílio e aos nematoides do gênero Meloidogyne. A murcha-bacteriana, para a qual não existiam cultivares resistentes, era controlada pela rotação de culturas ou pelo plantio em áreas virgens (Lopes \& Ávila, 2005). No entanto, com o advento e a expansão do cultivo protegido nas Regiões Sul e Sudeste do Brasil, a murcha-bacteriana passou também a ser um dos principais problemas do tomateiro dentro deste sistema de produção. Isso se deve à dificuldade de rotação de culturas por questões econômicas, que resulta na intensificação do cultivo sucessivo do tomateiro, contribuindo para o aumento gradativo da população bacteriana no solo. Além disso, temperaturas altas no interior de estufas e o uso de "mulch" de plástico favorecem a multiplicação da bactéria no solo, agravando a intensidade da doença. A proibição da comercialização do brometo de metila é outro fator que tem dificultado um controle mais eficiente de patógenos de solo, em especial em cultivo protegido, onde era intensamente usado para a desinfestação de solo (Martin, 2003).

Para o controle da murcha-bacteriana, o porta-enxerto resistente pode ser um genótipo de tomateiro ou de outras solanáceas resistentes pertencentes a espécies ou gêneros distintos, sendo mais conhecidas as várias espécies de "jurubebas" (gênero Solanum subgênero Leptostemonum), o jiló e a berinjela (Goto et al., 2003). Entretanto, a utilização de acessos do próprio tomateiro como porta-enxerto tem a vantagem de reduzir o problema de incompatibilidade associada ao uso de espécies/gêneros diferentes. Além disso, essa estratégia simplifica a operação de enxertia, pois o enxerto e o porta-enxerto podem ser plantados simultaneamente. Por outro lado, a combinação tomateiro-tomateiro não oferece proteção tão alta como aquela obtida pela combinação com outras espécies e gêneros da família Solanaceae. Isso porque os híbridos de tomateiro para uso como porta-enxertos disponíveis atualmente no mercado proporcionam resistência incompleta, variando de efetividade em função do isolado bacteriano presente e/ou das condições ambientais favoráveis à doença (alta população do patógeno, alta umidade e alta temperatura) (Lopes, 2009). Assim, uma determinada combinação tomateiro-tomateiro pode não ser totalmente efetiva para locais onde a pressão de inóculo é alta, como nas Regiões Norte e Nordeste do Brasil, ou em cultivos protegidos conduzidos em condições de alta temperatura e cultivos sucessivos de tomateiro e ou pimentão (Capsicum annuum) onde a doença já se apresenta com alta incidência.

Atualmente, poucos portaenxertos de tomateiro resistentes à murcha-bacteriana estão disponíveis no mercado brasileiro, dentre eles os híbridos 'Guardião', 'Protetor' e 'Muralha' (Takii do Brasil ${ }^{\circledR}$ ) e 'Magnet' (Sakata Seed Sudamérica ${ }^{\circledR}$ ) (Tabela 1). Com a finalidade de controlar a murcha-bacteriana em tomateiro, Sirtoli et al. (2011) avaliaram a combinação do híbrido comercial 'Platinum' com os porta-enxertos híbridos 'R601', 'R602', 'R603' (Eagle/BHN Seeds ${ }^{\circledR}$ ), 'Guardião' e 'Protetor' (Takii do Brasil ${ }^{\circledR}$ ), 'Spirit' (Nunhems do Brasil ${ }^{\circledR}$ ) e 'Magnet' (Sakata Seed Sudamérica ${ }^{\circledR}$ ). De acordo com esses autores, o uso da enxertia não alterou o desenvolvimento das plantas ou a qualidade de frutos em nenhuma das combinações avaliadas. No entanto, os porta-enxertos 'R603' e 'Magnet' proporcionaram maior sobrevivência das plantas (100\%). Este resultado, entretanto, deve ser analisado com certa restrição, pois o teste foi realizado em condições de solo com baixa infestação com $R s$ e/ou em um ambiente desfavorável à doença, como indicado pelos índices de sobrevivência acima de $90 \%$ observados na testemunha suscetível ao final do experimento.

Neste contexto, o objetivo deste trabalho foi avaliar a resistência de alguns porta-enxertos de tomateiro disponíveis no mercado brasileiro à murcha-bacteriana, levando em conta o grau de infestação do solo e a variabilidade patogênica de um conjunto de isolados de $R s$ obtidos de plantas de tomateiro.

\section{MATERIAL E MÉTODOS}

Os experimentos foram realizados em casa de vegetação da Embrapa Hortaliças, Brasília-DF. Foram avaliados os porta-enxertos híbridos comerciais 'Guardião', 'Muralha', 'Protetor' e 'Magnet', em comparação com a linhagem 'Hawaii 7996' (utilizada internacio- 
nalmente como testemunha resistente) (Wang et al., 1998). A linhagem 'L390', padrão internacional de suscetibilidade (Wang et al., 1998), foi usada como testemunha suscetível. Sementes desses genótipos foram semeadas simultaneamente em bandejas de isopor com 128 células contendo substrato Bioplant ${ }^{\circledR}$ estéril. As bandejas foram colocadas em suporte de ferro e irrigadas com moderação para evitar acúmulo de água sob as bandejas e minimizar a ocorrência de tombamento de mudas causado por oomicetos. Após a germinação, as mudas foram desbastadas, deixando-se apenas uma muda por célula, e adubadas com Basacote Mini $3 \mathrm{M}^{\circledR}$, estando prontas para a inoculação, com duas folhas completamente desenvolvidas (30 dias após a semeadura).

Experimento 1 / Desafio dos porta-enxertos com cinco isolados de $\boldsymbol{R s}$ obtidos de tomateiro no Brasil

Neste experimento, os isolados de $R s$ usados na inoculação foram CNPH 322, CNPH 476, CNPH 488, CNPH 489 e CNPH 519, previamente selecionados da coleção de bactérias fitopatogênicas da Embrapa Hortaliças pela alta virulência em tomateiro bem como pela diversidade bioquímica e geográfica (Tabela 2). Esses isolados foram previamente avaliados, por inoculação artificial, quanto à sua virulência em plantas de tomateiro. O inóculo foi preparado cultivando-se os isolados em meio de Kelman sem tetrazólio por 48 horas a $28^{\circ} \mathrm{C}$ (Kelman, 1954). Colônias típicas do patógeno de cada isolado foram diluídas em água estéril e a suspensão bacteriana ajustada por meio de densidade ótica para aproximadamente $10^{8} \mathrm{ufc} / \mathrm{mL}$.

As mudas foram inoculadas pela pulverização de suas raízes, expostas no bloco de substrato ao serem retiradas das células das bandejas, com aproximadamente $5 \mathrm{~mL}$ aplicados por planta. Imediatamente após a inoculação, as mudas foram transplantadas para vasos de plástico com capacidade de 1,5 L contendo partes iguais de substrato comercial e mistura de solo padrão da Embrapa Hortaliças. Esta mistura, de pH 6,5, foi composta de $85 \%$ de subsolo do cerrado (LVE) peneirado, 5\% de casca de arroz seca e $10 \%$ de casca de arroz carbonizada, enriquecida com 100 g de calcário dolomítico, 200 g de superfosfato simples e $60 \mathrm{~g}$ de sulfato de amônio para cada 100 L de substrato. Os vasos foram previamente desinfestados, mergulhando-os por 10 minutos em solução a 5\% de hipoclorito de sódio, e deixados secar por 48 horas. Cada parcela foi constituída de três vasos com duas plantas, em três repetições, totalizando 18 plantas inoculadas para cada combinação de isolado e genótipo. As plantas inoculadas foram mantidas em casa de vegetação $\left(21\right.$ a $\left.39^{\circ} \mathrm{C}\right)$ com irrigações diárias e aquecimento noturno, por meio de resistências elétricas acopladas a ventiladores. O aquecimento suplementar, controlado por termostato, evitou que as temperaturas da casa de vegetação atingissem valores inferiores a $20^{\circ} \mathrm{C}$, que favorecem a ocorrência de escapes.

$\mathrm{O}$ delineamento experimental utilizado foi inteiramente casualizado, com seis genótipos, cinco isolados e três repetições. As avaliações foram feitas a cada dois ou três dias com base na incidência de plantas doentes, considerada positiva quando mais da metade das folhas e folíolos encontrava-se murcha. Foram usadas para análise as leituras de sete e 13 dias após a inoculação. A análise estatística foi realizada por meio do programa SISVAR (UFLA, 2012), com a separação das médias pelo teste de Tukey a $5 \%$.

\section{Experimento 2 / Reação dos porta-enxertos em solos infestados}

No segundo experimento, as mudas dos porta-enxertos foram transplantadas em caixas de plástico de 40×30×10 cm, previamente esterilizadas com hipoclorito de sódio como no primeiro experimento, e contendo a mesma mistura de solo já indicada, porém previamente infestada com o patógeno. A infestação da mistura de solo foi feita plantando-se mudas de tomateiro 'San Vito', suscetível à murcha-bacteriana, com três pares de folhas definitivas produzidas em bandejas de isopor contendo 128 células. Antes do plantio, as mudas foram retiradas das bandejas e suas raízes, expostas nos blocos de substrato, pulverizadas com suspensão bacteriana contendo aproximadamente $10^{8} \mathrm{UFC/}$
$\mathrm{mL}$ do isolado $R s$ CNPH 489 (Raça 1 / biovar 1 / Filotipo II), originado de Borrazópolis-PR. Em cada bandeja, que continha aproximadamente $10 \mathrm{~kg}$ de mistura de solo, foram plantadas 12 mudas.

As bandejas foram colocadas em casa de vegetação com temperaturas mantidas, por meio de ventilação natural e aquecimento noturno, entre 20 e $38^{\circ} \mathrm{C}$. Quinze dias após a inoculação, as plantas, então murchas pela ação do patógeno, foram retiradas e, imediatamente, novas mudas de tomate 'San Vito', no estádio de duas folhas definitivas, foram plantadas, nove plantas por bandeja, desta vez sem inoculação das raízes. As bandejas foram consideradas infestadas após perceber-se que, a partir de 20 dias após o transplante, a maioria das mudas não inoculadas passaram a apresentar sintomas de murcha. Por meio do teste do copo (Lopes \& Ávila, 2005) constatou-se que a causa da murcha era mesmo induzida por $R s$.

Neste experimento, foram usadas seis bandejas, sendo que cada parcela consistiu de uma linha de seis plantas no sentido maior da bandeja. Em cada bandeja foram plantadas três linhas, cada uma com um dos mesmos genótipos e no mesmo estádio de desenvolvimento do experimento anterior, sendo necessárias duas bandejas por repetição, em três repetições. As avaliações foram feitas como no primeiro experimento, porém em intervalos de cinco dias, em virtude do desenvolvimento mais lento da doença em função de a inoculação ter sido menos drástica de modo a melhor simular uma condição natural de infestação de solo. A análise estatística foi realizada com a leitura realizada aos 25 dias após o plantio, quando observou-se a estabilização do número de plantas murchas na testemunha suscetível. Para a análise, usou-se o programa SISVAR (UFLA, 2012), com a separação das médias pelo teste de Tukey a $5 \%$.

\section{RESULTADOS E DISCUSSÃO}

\section{Desafio dos porta-enxertos com os isolados de $R s$}

As condições para desenvolvimento da murcha-bacteriana foram favoráveis e, três dias após a inoculação, foram 
Tabela 1. Resistências a doenças encontradas em porta-enxertos de tomateiro resistentes à murcha-bacteriana* (resistance to diseases in tomato rootstocks resistant to bacterial wilt). Brasília, Embrapa Hortaliças, 2013.

\begin{tabular}{llll}
\hline Porta-enxerto & Empresa & Genética & \multicolumn{1}{c}{ Resistências** $^{*}$} \\
\hline Magnet & Sakata & Híbrido & Rs, V (1), Fol (1 e 2), Forl, Pl, ToMV, Mj, Mi (1,2 e 3) \\
Guardião & Takii & Híbrido & Rs, V (1 e 2), Fol (1 e 2), Forl, ToMV, Ma, Mj, Mi \\
Protetor & Takii & Híbrido & Rs, V, F, Forl, Ma, Mj, Mi, ToMV \\
Muralha & Takii & Híbrido & Rs, nematoides, V, Fol, ToMV \\
Hawaii 7996 (H7996) & - & Variedade & Rs \\
\hline
\end{tabular}

*Informações obtidas de catálogos das respectivas empresas (informations obtained from catalogues published by the seed companies);

**Resistências: Rs: Murcha-bacteriana (Ralstonia solanacearum); V: Murcha de verticílio (Verticillium spp.); Fol: Murcha de fusário (Fusarium oxysporum f.sp. lycopersici); Forl: Podridão da coroa e da raiz (Fusarium oxysporum f.sp. radicis-lycopersici); ToMV: Mosaico do tomateiro (Tomato mosaic virus); Ma: (Meloidogyne arenaria); Mi: (Meloidogyne incognita); Mj: (Meloidogyne javanica) \{resistances: Rs: bacterial wilt (Ralstonia solanacearum); V: Verticillium wilt (Verticillium spp.); Fol: Fusarium wilt (Fusarium oxysporum f.sp. lycopersici); Forl: Crown root rot (Fusarium oxysporum f.sp. radicis-lycopersici); ToMV: Mosaic (Tomato mosaic virus); Ma: (Meloidogyne arenaria); Mi: (Meloidogyne incognita); Mj: (Meloidogyne javanica)\}.

Tabela 2. Isolados de Ralstonia solanacearum Raça 1 usados na inoculação de mudas de porta-enxertos de tomateiro (isolates of Ralstonia solanacearum Race 1 used to inoculate seedlings of tomato rootstocks). Brasília, Embrapa Hortaliças, 2013.

\begin{tabular}{lllcc}
\hline Isolado & Hospedeiro & Procedência & Biovar/Filotipo & Ano de isolamento \\
\hline CNPH 322 & Tomate & Tocantins & 3/I & 2008 \\
CNPH 476 & Tomate & Maranhão & 3/I & 2011 \\
CNPH 488 & Tomate & Paraná & 2/ II & 2012 \\
CNPH 489 & Tomate & Paraná & 1 / II & 2012 \\
CNPH 519 & Tomate & Goiás & 1/II & 2013 \\
\hline
\end{tabular}

observadas, para algumas combinações isolado $x$ genótipo, plantas em início de murchamento nas horas mais quentes do dia. A evolução da doença ocorreu de forma rápida na testemunha suscetível (linhagem 'L390'). Das seis avaliações efetuadas, decidiu-se por analisar duas: a primeira aos sete dias após a inoculação, quando todas as plantas da testemunha suscetível ('L390') apresentavam-se murchas quando inoculadas com a maioria dos isolados, e a segunda, aos 13 dias, quando o isolado mais virulento provocou murcha em todas as plantas da testemunha resistente ('H7996').

Ocorreu clara distinção entre os genótipos quanto quando se avaliou a incidência da doença, porém a reação desses genótipos foi dependente do isolado (Figura 1), conforme indicado pela interação genótipo $\mathrm{x}$ isolados na análise estatística. A discrepante reação de genótipos de tomateiro em relação às biovares ou outra classificação de $R s$ é amplamente conhecida e deve ser levada em conta em programas de me- lhoramento genético visando resistência à murcha-bacteriana em diferentes espécies de plantas hospedeiras (Lopes et al., 1994; Lopes \& Boiteux, 2004; Carmeille et al., 2006; Wicker et al., 2007).

De um modo geral, os porta-enxertos mais resistentes foram 'Muralha' e 'Guardião', que não diferiram entre si e da testemunha resistente ('Hawaii 7996') para a maioria dos isolados, porém, para algumas combinações, tiveram comportamento superior em relação ao 'Magnet' e 'Protetor' (Figura 1). Entretanto, 'Muralha' e 'Guardião', mesmo sendo os mais resistentes do grupo avaliado, não resistiram à alta virulência do isolado CNPH 488, que provocou a morte de $100 \%$ das plantas aos 11 dai (Figura 1). A enxertia de tomateiro em tomateiro, portanto, pode não ser efetiva sob condições favoráveis à murcha-bacteriana na presença de isolados altamente virulentos, como o CNPH 488.

\section{Reação dos porta-enxertos em solo infestado}

O plantio dos porta-enxertos em solo artificialmente infestado (Experimento 2), com menor pressão de inóculo, comprovou a efetividade dessa técnica como medida auxiliar no controle da murcha-bacteriana (Figura 2). Neste ensaio, foram observados menores índices de doença nos híbridos 'Guardião'e 'Muralha', informação que diverge do resultado de Sirtoli et al. (2011), que destacaram 'Magnet' como o híbrido mais resistente em relação ao 'Guardião' e 'Protetor' por ter proporcionado total sobrevivência das plantas. No entanto, a condição em que o teste foi realizado não foi favorável à doença ao permitir a sobrevivência de mais de $90 \%$ da testemunha suscetível ao final do experimento.

Nossos resultados indicam que alguns híbridos comerciais disponíveis no mercado oferecem significativa proteção contra a murcha-bacteriana em situações de baixa pressão de inóculo no solo e/ou condição de temperatura e umidade pouco favoráveis à doença. Reforçam ainda a constatação de que, sob alta pressão do inóculo (alta virulência e/ou alta população do patógeno), condições ambientais favoráveis e presença de isolados muito virulentos, combinações que podem ocorrer com frequência na Região Norte do País e sob cultivo protegido, dificilmente a enxertia de tomateiro em tomateiro per se proporcionará alta proteção da planta 


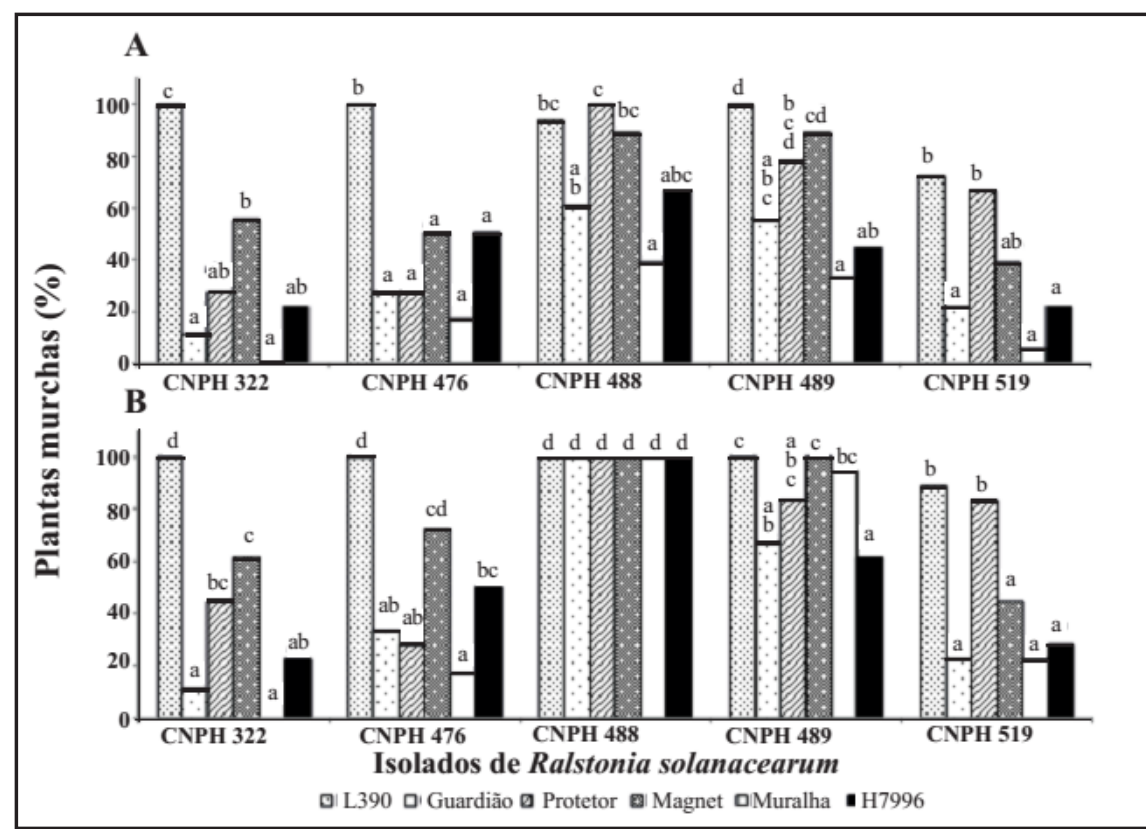

Figura 1. Comportamento, aos sete (A) e 13 (B) dias após a inoculação, de porta-enxertos de tomateiro inoculados com Ralstonia solanacearum em casa de vegetação. Barras identificadas com a mesma letra para cada conjunto de isolados não diferem entre si (Tukey, $5 \%$ ) \{performance, at seven (A) and 13 (B) days after inoculation, of tomato rootstocks inoculated with Ralstonia solanacearum in a greenhouse). Bars identified with same letters for each bacterial isolate do not differ (Tukey, 5\%)\}. Brasília, Embrapa Hortaliças, 2013.

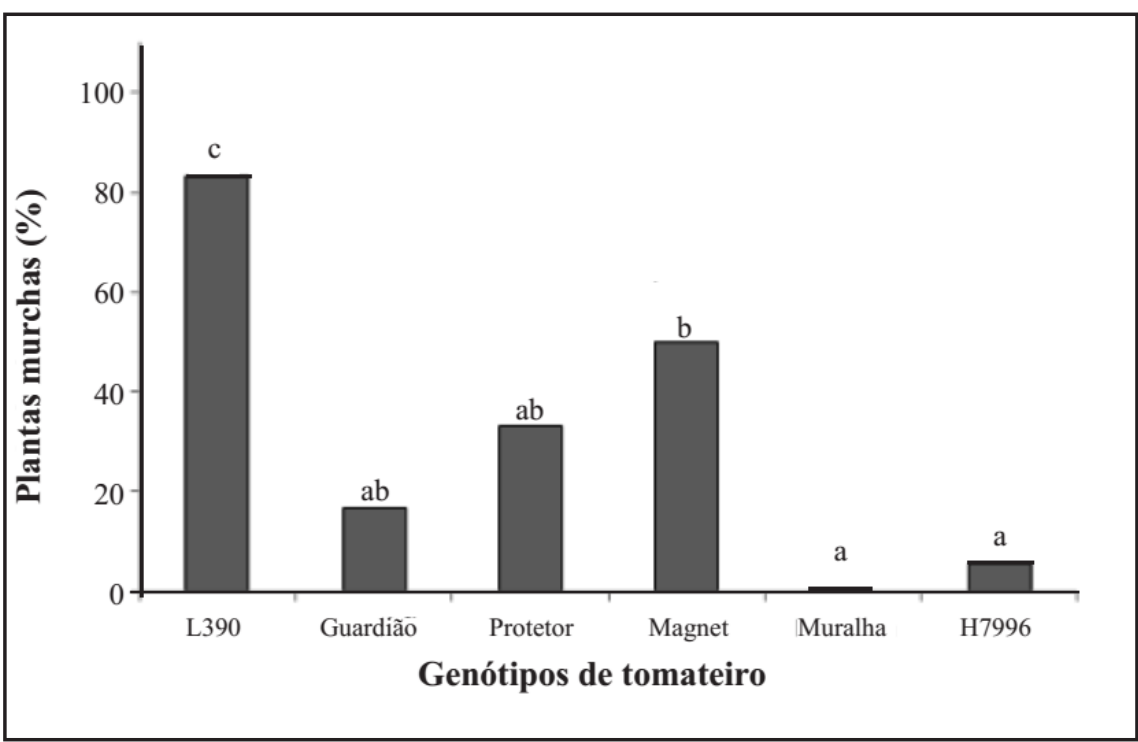

Figura 2. Comportamento de porta-enxertos de tomateiro quando mudas foram plantadas em solo artificialmente infestado com o isolado CNPH 476 de Ralstonia solanacearum (performance of tomato rootstocks when seedlings were transplanted to soil artificially infested with isolate CNPH 476 of Ralstonia solanacearum). Brasília, Embrapa Hortaliças, 2013.

enxertada contra a murcha-bacteriana. Tal situação exige medidas preventivas complementares de controle que visem a reduzir a população do patógeno no solo ou escolha de ambiente menos propício
(2012) em campos no sul dos EUA com diferentes níveis de infestação do solo e/ou com condições mais favoráveis à instalação da doença.

Além dos híbridos avaliados, a linhagem 'Hawaii 7996' proporcionou controle significativo da murcha-bacteriana do tomateiro. Esta linhagem é uma referência internacional de resistência a $R s$ em virtude de ter se destacado em testes realizados em diferentes países, inclusive no Brasil (Wang et al., 1998). Além disso, 'Hawaii 7996' apresenta boa compatibilidade com cultivares comerciais em termos de qualidade de frutos (Cardoso et al., 2006). O inconveniente dessa linhagem é que ela não possui resistência aos nematoides de galhas (Meloidogyne spp.), que normalmente coexistem com $R s$ em solos tropicais, e a outros patógenos de solo, quando comparada com os híbridos comerciais (Tabela 1). Além de não proteger a planta contra o ataque direto dos nematoides de galhas, em especial, essa linhagem ainda poderá perder parte da sua resistência à murcha-bacteriana por conta dos ferimentos causados pelos nematoides, que servem como vias de penetração de $R s$ (Deberdt et al., 1999). Neste aspecto, outras espécies de Solanum podem ser avaliadas alternativamente como porta-enxertos mais efetivos na proteção contra um espectro maior de patógenos, como genótipos de berinjela, jiló, cubiu ou jurubeba, desde que problemas de compatibilidade sejam resolvidos.

A planta enxertada tem um preço significativamente mais alto do que o de muda convencional em função do custo adicional de aquisição das sementes do porta-enxerto (normalmente híbridos) e do custo da mão de obra para a operação da enxertia. Em situações específicas de áreas sabidamente com histórico da murcha-bacteriana, a enxertia pode ser economicamente viável, pois além de viabilizar o cultivo do tomateiro, pode proporcionar maior produtividade (em relação a plantas não enxertadas) em algumas combinações enxerto/porta-enxerto, o que compensa os gastos maiores com a formação das mudas (Mohammed 
et al., 2009; Freeman et al., 2010).

\section{AGRADECIMENTOS}

Os autores Carlos A Lopes e Leonardo S Boiteux agradecem a concessão da bolsa de produtividade em pesquisa do $\mathrm{CNPq}(\mathrm{MCT})$.

\section{REFERÊNCIAS}

BAPTISTA MJ; REIS JUNIOR FB; XAVIER GR; ALCÂNTARA C; OLIVEIRA AR; SOUZA RB; LOPES CA. 2007. Eficiência da solarização e biofumigação do solo no controle da murcha-bacteriana do tomateiro no campo. Pesquisa Agropecuária Brasileira 42: 933-938.

CARDOSO SC; SOARES ACF; BRITO AS; CARVALHO LA; PEIXOTO CC; PEREIRA MEC; GOES E. 2006. Qualidade de frutos de tomateiro com e sem enxertia. Bragantia 65: 269-274.

CARMEILLE A; PRIOR P; KODJA H; CHIROLEAU F; LUISETTI J; BESSE P. 2006. Evaluation of resistance to race 3, biovar 2 of Ralstonia solanacearum in tomato germplasm. Journal of Phytopathology 154: 398-402.

CHENG SS; CHU EY. 2002. 'Pará Belo', um clone do tomateiro adaptado à Amazônia Oriental. Horticultura Brasileira 20: 516-519.

CHENG SS; SILVA MM. 1988. C-38 N, nova cultivar de tomate tolerante à murchabacteriana para trópico úmido brasileiro. Horticultura Brasileira 6: 50.

DEBERDT P; QUÉNÉHERVÉ P; DARRASSE A; PRIOR P. 1999. Increased susceptibility to bacterial wilt in tomatoes by nematode galling and the role of the $\mathrm{Mi}$ gene in resistance to nematodes and bacterial wilt. Plant Pathology 48:408-414.

FREEMAN J; PARET M; McAVOY T; OLSON S; RIDEOUT S. 2010. Utilization of grafted tomato seedlings for bacterial wilt resistance in open field production. Disponível em http:// mbao.org/2010/Proceedings/044FreemanJGra ftedTomato.pdf. Acessado em 15 de setembro de 2013.

GALLI F; TOKESHI H; CARVALHO PCT;
BALMER E; KIMATI H; CARDOSO CON; SALGADO CL. 1968. Manual de Fitopatologia: doenças das plantas e seu controle. São Paulo: Ceres. 640 p.

GOTO R; SANTOS HS; CAÑIZARES KAL. 2003. Enxertia em hortaliças. Botucatu: Editora UNESP. p. 86.

IOANNOU N. 2001. Integrating soil solarization with grafting on resistant rootstocks for management of soil-borne pathogens of eggplant. Journal of Horticultural Science and Biotechnology 76:396-401.

KELMAN A. 1954. The relationship of pathogenicity in Pseudomonas solanacearum to colony appearance on a tetrazolium medium. Phytopathology 44:693-695.

KUBOTA C; MCCLURE MA; KOKALISBURELLE N; BAUSHER MG; ROSSKOPF EN. 2008. Vegetable grafting: history, use, and current technology status in North America. HortSience 43:1664-1669.

LEE J-M; ODA M. 2003. Grafting of herbaceous vegetable and ornamental crops. In: JANICK J. (ed.). Horticultural Reviews, New York, NY v. 28: John Wiley \& Sons. p. 61-124.

LOPES CA. 2009. Murcha-bacteriana ou murchadeira - uma inimiga do tomateiro em climas quentes. Disponível em http:// bbeletronica/versaomodelo/html/2009/cot/ cot 67.shtml. Acessado em 10 de setembro de 2013.

LOPES CA; AVILA AC. 2005. (Organizadores). Doenças do tomateiro. Brasília: Embrapa Hortaliças.

LOPES CA; BOITEUX LS. 2004. Biovar-specific and broad-spectrum sources of resistance to bacterial wilt (Ralstonia solanacearum) in Capsicum. Crop Breeding and Applied Biotechnology 4: 350-355.

LOPES CA; QUEZADO-SOARES A M; MELO PE. 1994. Differential resistance of tomato cultigens to biovars I and III of Pseudomonas solanacearum. Plant Disease 78: 1091-1094.

MARTIN FN. 2003. Development of alternative strategies for management of soilborne pathogens currently controlled with methyl bromide. Annual Review of Phytopathology 41: 325-350.

MOHAMMED SMT; HUMIDAN M; BORAS M; ABDALLA OA. 2009. Effect of grafting tomato on different rootstocks on growth and productivity under glasshouse conditions. Asian Journal of Agricultural Research 3:
$47-54$.

NODA H; MACHADO FM; SILVA FILHO DF. 1988. Yoshimatsu, cultivar de tomate para cultivo no Trópico Úmido. Horticultura Brasileira 6: 70.

NODA H; VON-DER PAHLEN A; SILVA FILHO DF. 1986. Avaliação da resistência de progênies de tomate à murcha-bacteriana em solo naturalmente infestado por Pseudomonas solanacearum (Smith) Dows.). Revista Brasileira de Genética 9: 55-66.

PENA MA; NODA H; MACHADO FM; PAIVA MSS. 2010. Adaptabilidade e estabilidade de genótipos de tomateiro sob cultivo em solos de terra firme e várzea da amazônia infestados por Ralstonia solanacearum. Bragantia 69: 27-37.

RIVARD CL; O'CONNELL S; PEET MM; WELKER RM; LOUWS FJ. 2012. Grafting tomato to manage bacterial wilt caused by Ralstonia solanacearum in the southeastern United States. Plant Disease 96: 973-978.

SILVEIRA EB; GOMES AMA; FERRAZ E; MARANHÃO EAA; MARIANO RLR. 1999. Identificação de progênies de tomateiro resistentes à murcha-bacteriana. Horticultura Brasileira 17: 6-10.

SIRTOLI LF; CERQUEIRA RC; RODRIGUES JD; GOTO R; BRAGA CL. 2011. Enxertia no desenvolvimento e qualidade de frutos de tomateiro sob diferentes porta-enxertos em cultivo protegido. Scientia Agraria Paranaensis 10: 15-22.

SOUZA NM; BLIND AD; SILVA FILHO DF; RODRIGUES HS; NODA H. 2013. Avaliação de linhagens e cultivares de tomate resistentes à murcha-bacteriana (Ralstonia solanacearum) desenvolvidas na Amazônia. Enciclopédia Biosfera 9: 400-410.

UFLA. 2012. Programa Sisvar. Disponível em http://www.dex.ufla.br/ danielff/softwares. $\mathrm{htm}$. Acessado em 15 de setembro de 2012.

WANG JF; HANSON P; BARNES JA. 1998. Worldwide evaluation of an international set of resistance sources to bacterial wilt in tomato. p.269-275 in: Prior, P.; Allen, C.; Elphinstone, J. (eds.). Bacterial wilt disease. Molecular and ecological aspects. Berlin: Springer INRA. $448 \mathrm{p}$.

WICKER E; GRASSART L; CORANSONBEAUDU R; MIAN D; GUILBAUD C; FEGAN M; PRIOR P. 2007. Ralstonia solanacearum strains from Martinique (French West Indies) exhibiting a new pathogenic potential. Applied and Environmental Microbiology 73:6790-6801. 